\title{
Association between neutrophil/lymphocyte ratio with ductus arteriosus patency in preterm newborns
}

\author{
Temel $\mathrm{MT}^{1}$, Coskun $\mathrm{ME}^{1}$, Akbayram $\mathrm{S}^{2}$, Demiryürek $\mathrm{AT}^{3}$ \\ Department of Pediatrics, Faculty of Medicine, University of Gaziantep, Gaziantep, Turkey. \\ t_bilgic@yahoo.com
}

\section{ABSTRACT}

OBJECTIVE: The aim of this study was to assess the influence of neutrophil to lymphocyte (N/L) ratio and platelet indices on patent ductus arteriosus (PDA) in preterm infants.

BACKGROUND: PDA is a common problem with potentially serious associated morbidities in preterm neonates. METHODS: Premature infants with hemodynamically significant PDA $(n=47)$ and a control group without PDA $(n=50)$ who were hospitalized in the neonatal intensive care unit were retrospectively evaluated. The characteristics, perinatal factors, N/L ratio, platelet counts and other platelet indices of the infants in both groups during the first 3 days of life were recorded.

RESULTS: Platelet counts were significantly lower in the patient group than in the control group $(p=0.0343)$. There was a marked positive correlation between body weight and N/L ratio in preterm infants with PDA ( $p=$ 0.0001). PDA was associated with low platelet count.

CONCLUSION: Our results showed that N/L ratio is positively correllated with body weight in PDA group. These data suggest that platelet counts and N/L ratio might be useful predictors for the early diagnosis and evaluation of the clinical course of PDA in preterm infants (Tab. 2, Ref. 28). Text in PDF www.elis.sk.

KEY WORDS: correlation, ductus arteriosus, neutrophil to lymphocyte ratio, platelet count, preterm infant.

\section{Introduction}

Patent ductus arteriosus (PDA) is one of the most common problems in preterm infants leading to potentially serious effects on several organ systems $(1,2)$. Its incidence varies inversely with gestational age and may be as high as $60 \%$ among those with extremely low gestational age and in very low birth weight infants (3-6). In full-term infants, is the postnatal closure of ductus arteriosus divided in two phases: the "functional" closure of the lumen caused by the smooth muscle constriction within 18 to 24 hours after birth; and "anatomical" occlusion occurs over the next few days or weeks. Increase in arterial $\mathrm{pO}_{2}$ and a drop in circulating $\mathrm{PGE}_{2}$ and blood pressure within the lumen of the ductus (caused by the drop in pulmonary vascular resistance) promotes constriction of the ductus (7-10). However, the precise mechanism responsible for ductal constriction is still controversial.

A growing body of evidence from recent studies suggests that platelets play a complex role in acute and chronic inflammatory diseases and in tumor cell activation and growth beyond hemosta-

${ }^{1}$ Department of Pediatrics, Faculty of Medicine, University of Gaziantep, Gaziantep, Turkey, ${ }^{2}$ Department of Pediatric Hematology, Faculty of Medicine, University of Gaziantep, Gaziantep, Turkey, and ${ }^{3}$ Department of Medical Pharmacology, Faculty of Medicine, University of Gaziantep, Gaziantep, Turkey

Address for correspondence: M.T. Temel, Dr, Department of Pediatrics, Faculty of Medicine, University of Gaziantep, 27310 Gaziantep, Turkey. Phone: +90.342.3606060/76491, Fax: +90.342 .3601617$ sis and wound repair (11-13). Besides the platelet count, different platelet parameters such as mean platelet volume (MPV), platelet distribution width (PDW) and plateletcrit (PCT) have also been investigated because these parameters may influence the reactivity of platelets (14-17).

The neutrophil/lymphocyte $(\mathrm{N} / \mathrm{L})$ ratio in the complete blood count, which is inexpensive and easy-to-perform test, is used as an inflammatory indicator especially in patients with cardiovascular disease (18-21). A higher neutrophil percentage or a lower lymphocyte percentage is thought to be associated with an increased inflammatory response $(11-14,18)$. The goal of this study was to determine a possible association between platelet indices and N/L ratio and the presence and/or closure of PDA in preterm newborns.

\section{Material and methods}

We retrospectively evaluated records of premature infants who were between 25 and 37 weeks of gestation (due date from last menstrual period). These infants had hemodynamically significant PDA diagnosed in the neonatal intensive care unit (NICU) of Gaziantep University Hospital between January 2015 and December 2015. Echocardiographical examination is routinely performed between 3 rd-5th day of life. Hemodynamically significant PDA was defined as one with an internal ductal diameter of $\geq 1.5 \mathrm{~mm}$ and/or with a left atrium/aortic root ratio $\geq 1.5$ echocardiographically. Infants with congenital heart disease, persistent pulmonary hypertension and gross congenital abnormalities were excluded. Patient characteristics including gestational age, gender, birth weight, presence of 
Tab. 1. Comparison of neonatal demographic and maternal factors between infants with PDA and control group without PDA.

\begin{tabular}{|c|c|c|c|}
\hline & Control $(\mathrm{n}=50)$ & PDA $(n=47)$ & $\mathrm{p}$ \\
\hline Gestational age (weeks) & $32.52 \pm 2.22$ & $31.85 \pm 2.94$ & 0.2067 \\
\hline Gender & & & 0.9265 \\
\hline Male (n \%) & $24(48.0)$ & $23(48.9)$ & \\
\hline Female $(\mathrm{n} \%)$ & $26(52.0)$ & $24(51.1)$ & \\
\hline Birth weight (total, g) & $1858.90 \pm 583.58$ & $1756.04 \pm 777.54$ & 0.4613 \\
\hline VLBW $(\leq 1500 \mathrm{~g}, \mathrm{n}=12)$ & $1114.92 \pm 308.71$ & $1054.45 \pm 282.00$ & 0.3173 \\
\hline Birth weight $(>1500 \mathrm{~g}, \mathrm{n}=38)$ & $2093.84 \pm 431.84$ & $2275.74 \pm 593.63$ & 0.0863 \\
\hline \multicolumn{4}{|l|}{ Maternal history } \\
\hline Preeclampsia/eclampsia, n (\%) & $11(22.0)$ & $10(21.3)$ & 1.0000 \\
\hline EMR, n (\%) & $8(16.0)$ & $3(6.4)$ & 0.2015 \\
\hline Chorioamnionitis, $\mathrm{n}(\%)$ & $2(4.0)$ & $3(6.4)$ & 0.6712 \\
\hline Multiple births, n (\%) & $23(46.0)$ & $34(72.3)$ & 0.0152 \\
\hline Mother's age (years) & $28.92 \pm 5.14$ & $30.76 \pm 5.67$ & 0.0970 \\
\hline \multicolumn{4}{|l|}{ Accompanying diseases, $\mathrm{n}(\%)$} \\
\hline RDS & $5(10.0)$ & $10(21.3)$ & 0.1632 \\
\hline NEC, stage $2-3$ & $7(14.0)$ & $4(8.5)$ & 0.5262 \\
\hline Sepsis, early-onset & $4(8.0)$ & $3(6.4)$ & 1.0000 \\
\hline Pneumonia & $7(14.0)$ & $11(23.4)$ & 0.2990 \\
\hline Ibuprofen treatment & - & $24(51.1)$ & \\
\hline Paracetamol treatment & - & $7(14.9)$ & \\
\hline PDA ligation & - & $1(2.1)$ & \\
\hline PDA closure with drug treatment & - & $23(48.9)$ & \\
\hline PDA closure without drug treatment & - & $8(17.0)$ & \\
\hline Hemoglobin $(\mathrm{g} / \mathrm{dl})$ & $16.16 \pm 2.24$ & $15.66 \pm 3.11$ & 0.3637 \\
\hline Platelet count $\left(\times 10^{3} / \mathrm{mm}^{3}\right)$ & $254.58 \pm 83.19$ & $220.47 \pm 72.50$ & 0.0343 \\
\hline MPV (fl) & $10.02 \pm 0.94$ & $10.00 \pm 0.89$ & 0.9147 \\
\hline PCT $(\%)$ & $0.25 \pm 0.08$ & $0.22 \pm 0.07$ & 0.0529 \\
\hline PDW $(\%)$ & $11.15 \pm 1.77$ & $11.27 \pm 2.14$ & 0.7636 \\
\hline Neutrophils $\left(\times 10^{3} / \mathrm{mm}^{3}\right)$ & $6.13 \pm 3.61$ & $6.05 \pm 5.38$ & 0.9313 \\
\hline Lymphocytes $\left(\times 10^{3} / \mathrm{mm}^{3}\right)$ & $3.69 \pm 1.47$ & $3.54 \pm 1.50$ & 0.6201 \\
\hline Neutrophils/Lymphocytes ratio & $1.94 \pm 1.26$ & $2.06 \pm 2.06$ & 0.7431 \\
\hline
\end{tabular}

ECHO finding

Ductal diameter (mm)

$2.53 \pm 1.34$

Data show mean \pm SD values. PDA, patent ductus arteriosus; MPV, mean platelet volume; PDW, platelet distribution width; RDS, respiratory distress syndrome; EMR, early membrane rupture; VLBW, very low birth weight; PCT, plateletcrit. PCT is calculated according to the following formula (28): PCT = platelet count $\mathrm{x}$ MPV/10 000.

accompanying disease [respiratory distress syndrome (RDS), necrotizing enterocolitis (NEC), sepsis, and pneumonia], maternal risk factors including preterm prolonged rupture of membranes (EMR), chorioamnionitis and preeclampsia/eclampsia were reviewed for all infants. The control group consisted of preterm infants (the same range of gestational weeks) but without hemodynamically significant PDA on routine echocardiography in the NICU.

Complete blood counts were obtained both from the patients and controls during the first 3 days of life, mostly within the first $24 \mathrm{~h}$. Blood samples were taken from the umbilical vein and collected in ethylenediaminetetraacetic acid tubes. Platelet, neutrophil, lymphocyte counts and the other platelet indices including MPV, PDW and PCT of the infants in both groups were performed using the Coulter Counter model LH (Coulter electronics, Hialeah, FL, USA) and recorded. Ibuprofen or paracetamol treatment was started in infants with hemodynamically relevant PDA unless they had any contraindications. Treatment was withheld if platelet count was $<50,000 / \mathrm{mm}^{3}$. Within $24-48 \mathrm{~h}$ of completion of a course of medical treatment, echocardiography was repeated to evaluate the closure of ductus arteriosus. The study was undertaken in compliance with the guidelines of the Declaration of Helsinki, and it was approved by the local Ethics Committee.

\section{Statistical analyses}

Data were expressed as mean \pm standard deviation (SD) or percentage. Statistical analysis was performed using GraphPad Instat version 3.05 (GraphPad Software Inc., San Diego, CA, USA). For comparisons of the differences between mean values of two groups, the unpaired Student's t test was used. The Chi-square test for independence and the Fisher's exact tests were used for calculation of the significance of differences in genotype and allele frequencies. The Pearson's test was used to identify the correlations. All statistical tests and $\mathrm{p}$ values were two-sided, and $\mathrm{p}$ $<0.05$ was considered statistically significant.

\section{Results}

Comparison of the demographic features, antenatal and neonatal history, and accompanying diseases between the study groups are presented in Table 1. There were no differences between the study groups with regards to gestational age, birth weight and gender. When compared based on the maternal history, multiple births were significantly higher in the PDA group than in the control group $(p=0.0152)$. In 8 patients $(17 \%)$ platelet counts were $<150.000 / \mathrm{mm}^{3}$ in the PDA group, while this ratio was $6 \%$ 
Tab. 2. Correlations between the birth weight, $\mathrm{N} / \mathrm{L}$ ratio, and platelet indices in preterm infants with PDA.

\begin{tabular}{|c|c|c|c|}
\hline Parameters & Correlation coefficient (r) & Coefficient of determination $\left(\mathrm{r}^{2}\right)$ & $\mathrm{p}$ \\
\hline BW (total) $\leftrightarrow$ Platelet count (total) & 0.1231 & 0.0152 & 0.4096 \\
\hline BW (total) $\leftrightarrow$ MPV (total) & 0.1236 & 0.0153 & 0.4076 \\
\hline $\mathrm{BW}($ total) $\leftrightarrow \mathrm{PCT}$ (total) & 0.1494 & 0.0223 & 0.3162 \\
\hline BW (total) $\leftrightarrow$ PDW (total) & -0.0252 & 0.0006 & 0.8663 \\
\hline $\mathrm{BW}($ total $) \leftrightarrow \mathrm{N} / \mathrm{L}$ ratio & 0.6310 & 0.3982 & 0.0001 \\
\hline VLBW $(\leq 1500 \mathrm{~g}) \leftrightarrow$ Platelet count (VLBW) & 0.3291 & 0.1083 & 0.1565 \\
\hline $\operatorname{VLBW}(\leq 1500 \mathrm{~g}) \leftrightarrow \operatorname{MPV}(\mathrm{VLBW})$ & -0.2857 & 0.0816 & 0.2221 \\
\hline VLBW $(\leq 1500 \mathrm{~g}) \leftrightarrow \mathrm{N} / \mathrm{L}$ ratio & 0.5366 & 0.2879 & 0.1098 \\
\hline $\mathrm{BW}(>1500 \mathrm{~g}) \leftrightarrow$ Platelet count $(>1500 \mathrm{~g})$ & 0.1430 & 0.0205 & 0.4767 \\
\hline $\mathrm{BW}(>1500 \mathrm{~g}) \leftrightarrow \mathrm{MPV}(>1500 \mathrm{~g})$ & -0.1708 & 0.0292 & 0.3944 \\
\hline $\mathrm{BW}(>1500 \mathrm{~g}) \leftrightarrow \mathrm{PCT}(>1500 \mathrm{~g})$ & 0.0925 & 0.0086 & 0.6462 \\
\hline $\mathrm{BW}(>1500 \mathrm{~g}) \leftrightarrow \mathrm{N} / \mathrm{L}$ ratio & 0.6436 & 0.4142 & 0.0012 \\
\hline
\end{tabular}

BW, body weight; MPV, mean platelet volume; PCT, plateletcrit; PDW, platelet distribution width; N/L, Neutrophils/Lymphocytes; VLBW, very low birth weight

( 3 infants) in the control group $(\mathrm{p}=0.1140)$. Platelet count was significantly lower in the PDA group than in the control group $(\mathrm{p}=0.0343)$. MPV, PDW and PCT values were similar between the two groups.

Totally 31 patients out of 47 with PDA were treated with ibuprofen (24 infants, $51.1 \%$ ) and paracetamol (7 infants, 14.9 $\%)$, respectively. Closure of the ductus was reached in 23 patients $(48.9 \%)$ with single or repeated courses of drug treatment. Only one infant underwent surgical ligation $(2.1 \%)$ after failure of three treatment courses. None of the patients experienced any re-openings during follow-up. As a result, we found diminished platelet counts in the PDA grup, but no association with the other platelet indices were observed (Tab. 1).

Correlations between the birth weight and platelet indices and $\mathrm{N} / \mathrm{L}$ ratio in preterm infants with PDA were also assessed in this study (Tab. 2). Significant correlations were observed between body weight and N/L ratio. This correlation was present in preterms with $>1500 \mathrm{~g}$ body weight, but not with $\operatorname{VLBW}(\leq 1500 \mathrm{~g})$. This could be related to the low numbers of preterms $(n=12)$ in the VLBW group.

\section{Discussion}

Significant patency of ductus arteriosus, especially in preterm infants, is associated with life-threatening complications such as congestive heart failure, pulmonary edema and hemorrhage, prolonged requirement of ventilatory support, bronchopulmonary dysplasia, acute renal failure, intraventricular hemorrhage, and NEC $(1,2)$. Although several hypotheses have been introduced to date, the precise mechanisms of ductal closure were proposed to differ in preterm and full-term infants. In full-term infants, ductus closure is related with the decreasing blood flow both in the ductus lumen and vaso vasorum, leading to hypoxia in the vessel wall after birth. Platelet aggregation has a minor role in this setting. On the other hand, ductus arteriosus is much thinner in preterm infants and extracts the oxygen it needs from luminal blood after constriction of the ductus arteriosus. Decrease in the blood flow alone does not provide "sufficient" hypoxia and platelet aggregation is needed for permanent closure. Therefore, low platelet counts may result in increased risk of PDA in preterm infants (22).
Recently, Echtler et al (23) showed clear histological evidence of platelet accumulation within the lumen of the ductus arteriosus in newborn mice by using intravital microscopy, and identified that platelets are recruited to the constricting ductus arteriosus and initiate thrombotic occlusion of the ductus. They found a higher incidence of persistent ductus arteriosus in congenitally thrombocytopenic mice. Echtler et al (23) additionally evaluated premature infants in their clinic retrospectively to find out what is the clinical relevance of their findings and identified thrombocytopenia as an independent predictor for ductal patency. Similarly, Dani et al (16) demonstrated that ductus arteriosus is associated with low platelet count at birth, but not after $24-48 \mathrm{~h}$ of birth. In another study, Alyamac Dizdar et al (15) have studied 154 preterm infants born at 26-29 weeks of gestation and indicated that low platelet count and high PDW were independent risk factors of ductus arteriosus with hemodynamic relevance. A large-scale study of 1,350 infants with birth weights $<1500 \mathrm{~g}$ by Sallmon et al (24) found no relationship between platelet count on the first day of birth and patent ductus arteriosus. Sallmon et al (24) concluded that impaired platelet function due to immaturity and critical illnesses related with the patency of ductus arteriosus are connected with hemaodynamic relevance rather than the low platelet count. Similarly, Shah et al (14), and Olukman et al (25) could not find any relationship between low platelet counts and permanent ductal closure or ductal re-opening. In the study of Shah et al (14), the authors showed that full-term infants with severe thrombocytopenia, secondary to Wiskott-Aldrich syndrome or alloimmune thrombocytopenia do not have a higher incidence PDA. We have showed low platelet counts in infants with PDA indicating that platelet count may contribute to the development of PDA.

Like MPV, PDW is another marker which reflects the platelet activation invarious clinical conditions. In the literature, there are several studies that have found a significant association between elevated MPV and PDW values and severe inflammatory processes. Wasiluk et al (26) demonstrated higher MPV and lower PDW values in term infants when compared with preterm infants. However, Alyamac Dizdar et al (15) have reported that PDA was indepentdently associated with high PDW but not MPV. In contrast to these previous studies, we did not find any association between MPV and PDW values and the risk of ductal patency. Although 
491-494

PCT reflect the total platelet mass like PDW, we found no association in PCT between the patients and the control groups.

$\mathrm{N} / \mathrm{L}$ ratio has been recently defined as a novel potential inflammation marker in cardiovascular diseases (18-21). N/L ratio can easily be calculated using the peripheral blood count than measuring other inflammatory cytokines, such as IL-6, IL-1 $\beta$, and TNF- $\alpha$ (27). To our knowledge, there was no study investigating the correlation between body weight and N/L ratio in PDA infants.

In conclusion, to the best of our knowledge, our study is the first that investigates all platelet indices including MPV, PDW and PCT and another easy to perform test as an inflammatory marker, the N/L ratio, in patients with PDA. Our results showed that low platelet count is associated with PDA. The findings of this study demonstrated that $\mathrm{N} / \mathrm{L}$ ratio is positively correllated with body weight in PDA group. Since N/L ratio and birth weight are positively correlated, platelet counts and $\mathrm{N} / \mathrm{L}$ ratio might have a prognostic role for the early diagnosis and clinical course of PDA in preterm infants.

\section{References}

1. Sekar KC, Corff KE. Treatment of patent ductus arteriosus: indomethacin or ibuprofen? J Perinatol 2008; 28 (Suppl 1): S60-S62.

2. Koch J, Hensley G, Roy L, Brown S, Ramaciotti C, Rosenfeld CR. Prevalence of spontaneous closure of the ductus arteriosus in neonates at a birth weight of 1000 grams or less. Pediatrics 2006; 117 (4): 1113-1121.

3. Clyman RI. Mechanisms regulating the ductus arteriosus. Biol Neonate 2006; 89 (4): 330-335.

4. Sehgal A, McNamara PJ. The ductus arteriosus: a refined approach! Semin Perinatol 2012; 36 (2): 105-113.

5. Bancalari E, Claure N, Gonzalez A. Patent ductus arteriosus and respiratory outcome in premature infants. Biol Neonate 2005; 88 (3): 192-201.

6. Cherif A, Khrouf N, Jabnoun S, Mokrani C, Amara MB, Guellouze N, Kacem S. Randomized pilot study comparing oral ibuprofen with intravenous ibuprofen in very low birth weight infants with patent ductus arteriosus. Pediatrics 2008; 122 (6): e1256- e1261.

7. Hamrick SE, Hansmann G. Patent ductus arteriosus of the preterm infant. Pediatrics 2010; 125 (5): 1020-1030.

8. Hajj H, Dagle JM. Genetics of patent ductus arteriosus susceptibility and treatment. Semin Perinatol 2012; 36 (2): 98-104.

9. Hermes-DeSantis ER, Clyman RI. Patent ductus arteriosus: pathophysiology and management. J Perinatol 2006; 26 (Suppl 1): S14-S18.

10. Clyman RI, Chan CY, Mauray F et al. Permanent anatomic closure of the ductus arteriosus in newborn baboons: the roles of postnatal constriction, hypoxia, and gestation. Pediatr Res 1999; 45 (1): 19-29.

11. Huang HS, Chang HH. Platelets in inflammation and immune modulations: functions beyond hemostasis. Arch Immunol Ther Exp (Warsz) 2012; 60 (6): 443-451.
12. Katz JN, Kolappa KP, Becker RC. Beyond thrombosis: the versatile platelet in critical illness. Chest 2011; 139 (3): 658-668.

13. Leslie M. Cell biology. Beyond clotting: the powers of platelets. Science 2010; 328 (5978): 562-564.

14. Shah NA, Hills NK, Waleh N, McCurnin D, Seidner S, Chemtob S, Clyman R. Relationship between circulating platelet counts and ductus arteriosus patency after indomethacin treatment. J Pediatr 2011; 158 (6): 919-923.

15. Alyamac Dizdar E, Ozdemir R, Sari FN et al. Low platelet count is associated with ductus arteriosus patency in preterm newborns. Early Hum Dev 2012; 88 (10): 813-816.

16. Dani C, Poggi C, Fontanelli G. Relationship between platelet count and volume and spontaneous and pharmacological closure of ductus arteriosus in preterm infants. Am J Perinatol 2013; 30 (5): 359-364.

17. Boo NY, Mohd-Amin I, Bilkis AA, Yong-Junina F. Predictors of failed closure of patent ductus arteriosus with indomethacin. Singapore Med J 2006; 47 (9):763-768.

18. Zahorec R. Ratio of neutrophil to lymphocyte counts - rapid and simple parameter of systemic inflammation and stress in critically ill. Bratisl Lek Listy 2001; 102 (1): 5-14.

19. Aydin M, Yuksel M, Yildiz A et al. Association between the neutrophil to lymphocyte ratio and prehypertension. Bratisl Lek Listy 2015; 116 (8): 475-479.

20. Tamhane UU, Aneja S, Montgomery D, Rogers EK, Eagle KA, Gurm HS. Association between admission neutrophil to lymphocyte ratio and outcomes in patients with acute coronary syndrome. Am J Cardiol 2008; 102 (6): 653-657.

21. Núñez J, Núñez E, Bodí V et al. Usefulness of the neutrophil to lymphocyte ratio in predicting long-term mortality in ST segment elevation myocardial infarction. Am J Cardiol 2008; 101 (6): 747-752.

22. Clyman R, Chemtob S. Vessel remodeling in the newborn: platelets fill the gap. Nat Med 2010; 16 (1): 33-35.

23. Echtler K, Stark K, Lorenz M et al. Platelets contribute to postnatal occlusion of the ductus arteriosus. Nat Med 2010; 16 (1): 75-82.

24. Sallmon H, Weber SC, Hüning B et al. Thrombocytopenia in the first 24 hours after birth and incidence of patent ductus arteriosus. Pediatrics 2012; 130 (3): e623-e630.

25. Olukman O, Özdemir R, Karadeniz C, Calkavur S, Mese T, Vergin C. Is there a relationship between platelet parameters and patency of ductus arteriosus in preterm infants? Blood Coagul Fibrinolysis 2017; 28 (1): 8-13.

26. Wasiluk A, Osada J, Dabrowska M, Szczepański M, Jasinska E. Does prematurity affect platelet indices? Adv Med Sci 2009; 54 (2): $253-$ 255.

27. Turkmen K, Guney I, Yerlikaya FH, Tonbul HZ. The relationship between neutrophil-to-lymphocyte ratio and inflammation in end-stage renal disease patients. Ren Fail 2012; 34 (2): 155-159.

28. Beyan C, Beyan E. Plateletcrit may not be a marker for recurrent pregnancy loss. Clin Appl Thromb Hemost 2015; 21 (6): 588-589.

Received March 20, 2017. Accepted April 17, 2017. 